

\title{
Organometallic Metal Nanoparticles for Catalysis
}

\author{
M. Rosa Axet, Karine Philippot
}

\section{To cite this version:}

M. Rosa Axet, Karine Philippot. Organometallic Metal Nanoparticles for Catalysis. Karine Philippot; Alain Roucoux. Nanoparticles in Catalysis: Advances in Synthesis and Applications, Wiley-VCH, pp.73-97, 2021, 9783527346073. 10.1002/9783527821761.ch4 . hal-03235178

\section{HAL Id: hal-03235178 \\ https://hal.science/hal-03235178}

Submitted on 5 Nov 2021

HAL is a multi-disciplinary open access archive for the deposit and dissemination of scientific research documents, whether they are published or not. The documents may come from teaching and research institutions in France or abroad, or from public or private research centers.
L'archive ouverte pluridisciplinaire HAL, est destinée au dépôt et à la diffusion de documents scientifiques de niveau recherche, publiés ou non, émanant des établissements d'enseignement et de recherche français ou étrangers, des laboratoires publics ou privés. 


\title{
Organometallic metal nanoparticles for catalysis \\ By M. Rosa Axet and Karine Philippot*
}

\author{
Affiliation \\ Dr Karine Philippot* and Dr M. Rosa Axet \\ CNRS, LCC (Laboratoire de Chimie de Coordination), UPR8241, Université de Toulouse, \\ UPS, INPT, F-31077 Toulouse cedex 4, France \\ * E-mail: karine.philippot@lcc-toulouse.fr
}

\section{ORCID}

Karine Philippot: 0000-0002-8965-825X

M. Rosa Axet: 0000-0002-2483-1533

\section{Keywords}

nanoparticle; organometallic; molecular chemistry; nanochemistry; catalysis

\begin{abstract}
This chapter provides an overview of the recent advances in the development of metal nanoparticles by using the tools of molecular chemistry. The objective is to illustrate the interest of this synthesis approach through a selection of examples from our group concerning hydrogenation catalysis. We expose here the efforts that allowed reaching metal nanoparticles with specific characteristics and therefore to allow to study structure-properties relationships in a precise manner. We describe how the control of the nanoparticle surface properties by an appropriate choice of the stabilizing ligands impacts in catalytic performances.
\end{abstract}

\section{Introduction}

Assimilated to heterogeneous catalysts, metal nanoparticles (MNPs) have been known for a long time, but they have been received a renewed interest for the past three decades due to the necessity to design better defined nanocatalysts [1]. Common issues of heterogeneous catalysts are the size dispersity (e.g. 5\% in even highly monodispersed samples), the uncertain surface state, the sometimes unknown core/ligand interfaces, the defects and elusive structures in 2D materials, and the still missing information on alloy patterns in bi- and multimetallic NPs. Such disavantatges preclude deep understandings of many fundamental aspects, among which the knowledge on atomic-level mechanisms that can happen at their surface, a key point if one want to develop more performant nanocatalysts [2]. Looking for 
synthesis strategies which permit to access, in a reproducible manner, to well-defined MNPs in terms of size, crystalline structure, composition (metal cores and stabilizing agents), chemical order, shape and dispersion is thus a prerequisite in order to study finely their properties and conclude on the relationships between structural features and catalytic performances. In this context, the bottom-up liquid-phase techniques are helpful because of their high versatility and ease of use, and also, the straightforward equipments required than physic routes. Recent advances in solution nanochemistry allow having at disposal efficient synthesis tools to reach these objectives. Such evolution in the preparation of MNPs makes nanocatalysis as a key domain, at the borderline between homogeneous and heterogeneous catalyses [1]. Interestingly, ligand-stabilized MNPs offer a metal surface with both an interface close to that of molecular complexes, as isolated surface atoms can be seen like metal centers, with their coordination sphere and neighbouring metal atoms, like in pure metal surfaces. In these NPs both coordinated ligands and neighbouring metal atoms can affect the surface properties and consequently their catalytic performances. Ligand-capped MNPs are thus very attractive systems to perform surface studies as done with homogeneous catalysts while keeping benefit of metal atom assemblies. In parallel of nanochemistry progress, computational chemistry developments offer powerful tools to access to MNP structural information, including information on the capping ligands like their coordination modes and their influence on MNP surface state, as well as on their reactivity through mechanistic studies. Recent advances bring computational chemistry applied to small MNPs to the same level of accuracy and relevance as in molecular chemistry [3]. Thus, the alliance between nanochemistry and computational chemistry enables to have precise view of the surface properties of MNPs [4].

On the basis of the above, this chapter aims at first illustrating the interests of the organometallic approach for the synthesis of MNPs with a precise control of their characteristics. Then a selection of recent results obtained by our group, investigating nanocatalysts engineered following these concepts, will provide a view of the possibilities offered in terms of catalytic properties in hydrogenation reactions.

\section{Interests of the organometallic approach to study stabilizer effect on metal surface properties}

The synthesis of MNPs in organic solvents proved to be a versatile route to have a control on sizes, shapes, compositions and structures for catalytic studies. Being part of current nanochemistry, the organometallic approach (Figure 1) aims at using the molecular chemistry 
concepts, particularly those of coordination and organometallic chemistries, in order to develop efficient tools for a reproducible synthesis of well-defined soluble MNPs and explore their surface features. Being now applied by several academic research groups in the world, this approach is a well-established method to access model MNPs for investigations in catalysis. This strategy is based on the use of organometallic or metal-organic complexes as the precursors of metal atoms together with adequate stabilizers such as ionic liquids, polymers, ligands, but also inorganic and carbonaceous supports. It permits building diverse nano-objects with modulable sizes including ultra-small size $(c a .1-10 \mathrm{~nm})$ and a metallic surface free of contaminants, such as halides or other ions, and functionalisable at will. A major advantage with organometallic or metal-organic complexes is their facile decomposition in mild conditions (1-3 bar of $\left.\mathrm{H}_{2} ; \mathrm{T} \leq 150^{\circ} \mathrm{C}\right)$ by reduction or ligand displacement from the metal coordination sphere in the presence of a suitable amount of stabilizer, usually in an organic medium, but also described in aqueous media [5]. Olefinic complexes are generally preferred because when exposed to $\mathrm{H}_{2}$ pressure they lead to clean metal surfaces, as the formed alkanes are inert towards the growing MNP surface and can be easily eliminated by simple evaporation or/and by precipitation of MNPS and further filtration. Through this method, monodisperse assemblies of MNPs with an effective control of size, shape and surface state can be synthesized. The so-obtained MNPs can be finely characterised before their application in catalysis.

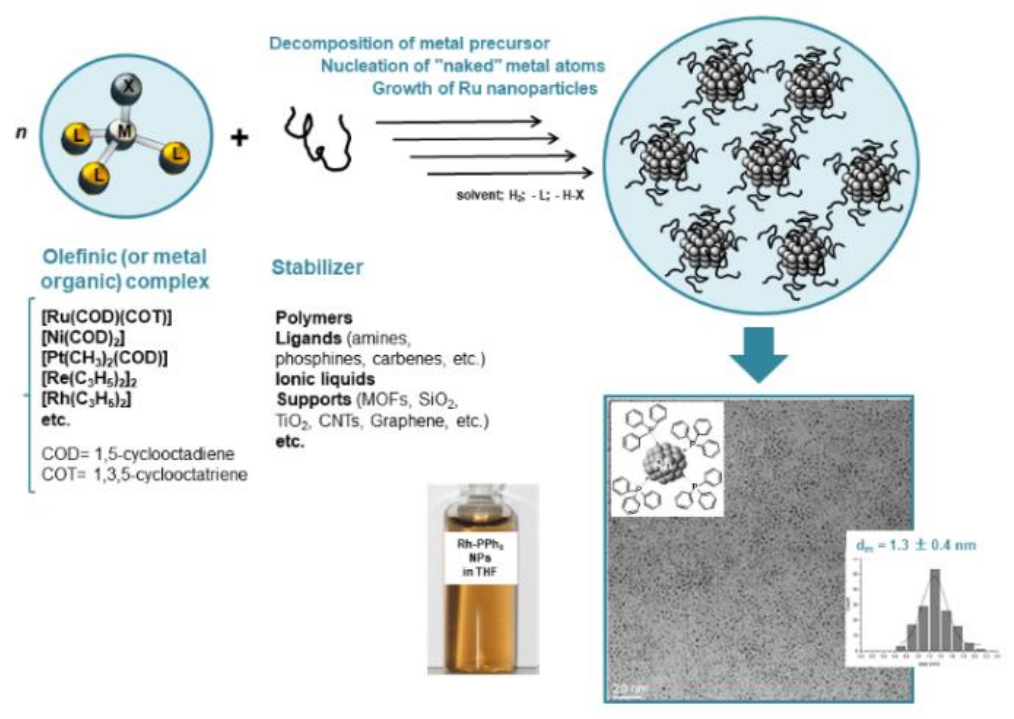

Figure 1. Organometallic approach for the synthesis of metal nanoparticles. 
Choosing the stabilizer is also essential as it intervenes at different levels, namely the growth, stability, solubility and surface properties and consequently on catalytic performance of the MNPs. Besides organic polymers (like polyvinylpyrrolidone, PVP) or ionic liquids [6] that provide steric and electrosteric stabilization, respectively and weak interaction with the metal surface, a large variety of organic ligands coordinating via $\mathrm{N}, \mathrm{O}, \mathrm{S}, \mathrm{Si}, \mathrm{P}$ or $\mathrm{C}$ atoms (as amines, carboxylic acids, thiols, silanes, phosphines, carbenes, fullerene, but also more sophisticated ligands) to the metal surface have been described [7]. By using water-soluble polymers (like PVP [8]) and ligands (such as 1,3,5-triaza-7-phosphaadamantane [9], or sulfonated phosphines [10], and also cyclodextrins [11]), the metal nanoparticles become transferable into water, thus leading to aqueous colloidal suspensions that offer other opportunities in catalysis as reported in Chapter 3 [12]. The organometallic approach is also very effective for accessing to controlled bimetallic NPs. Indeed, the adequate choice of the reaction conditions, such as metal precursors and reducing agents, allows governing the kinetics of metal atom generation to reach the target bimetallic chemical order: either alloyed, core-shell or surface decorated systems [13]. Immobilization of MNPs into alumina, silica or carbon materials [14] allowed improving stability and recovery of the nanomaterials and also taking benefit of the support properties during catalysis. This can be performed either by impregnation of a given support with a colloidal solution of preformed MNPs or by their direct synthesis in the presence of the support. Improvement of the NP grafting and stability was observed when using functionalized supports decorated at their surface with chemical groups similar to those involved in common stabilizing ligands (like amines for instance).

Fine characterization of the NPs is carried out by using combined techniques from both solid and molecular chemistry such as transmission electron microscopy (TEM), high resolution electron microscopy (HREM) or scanning transmission electron microscopy (STEM) coupled with energy dispersive X-ray (EDX), scanning transmission electron microscopy at high angle annular dark field (STEM-HAADF), X-ray diffraction (XRD), wide-angle X-ray scattering (WAXS), liquid and solid state NMR, Fourier transform IR, thermogravimetric analysis (TGA), inductively coupled plasma (ICP), elemental analysis, magnetic measurements, XRay photoelectron spectroscopy (XPS), among others. The combination of these tools allows obtaining detailed information of the NP systems. Even if the surface properties of Ru NPs have been extensively studied and described by means of those techniques (Figure 2) [4a, 15] the same methodology has been successfully applied to characterize other MNPs, such as Pt [16], Pd [17], Rh [18] , Ir [19], or Ni [20]. 


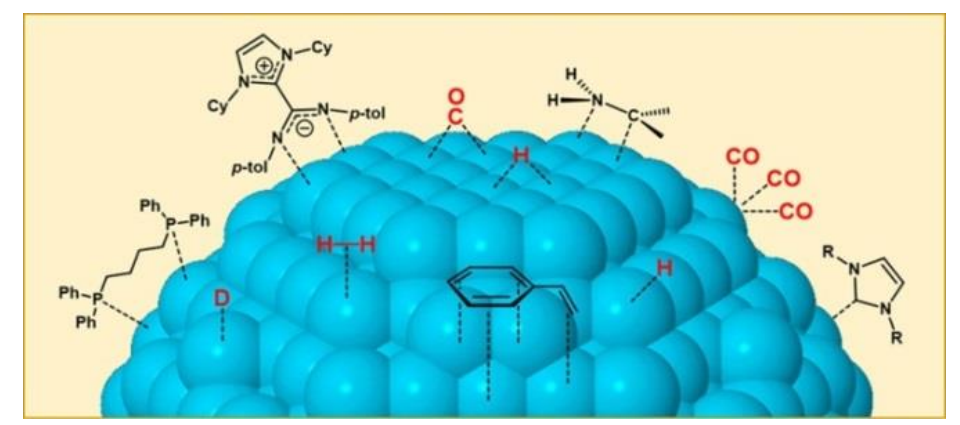

Figure 2. Schematic view of some surface studies performed on ruthenium nanoparticles. Reproduced with permission from [15a]. Copyright 2018 American Chemical Society.

Using $\mathrm{H}_{2}$ as reducing agent to synthesize MNPs gives rise to the adsorption of hydrogen atoms at the metal surface, a clear advantage for reduction catalysis. It has been shown that the surface hydrides content can vary depending on the others species present on the surface of Ru NPs and it is generally higher than 1 (1-1.3 H per surface Ru atom) [21] even into water [10]. However, on Ru NPs capped by carboxylate ligands the number of hydrides per surface $\mathrm{Ru}$ atom was found to be significantly lower (ca. $0.4 \mathrm{H} /$ surface $\mathrm{Ru}$ atom) by both experimental and theoretical techniques, as the result of the coordination mode of the carboxylate groups [4a]. These surface hydrides can also be displaced by coordination of $\mathrm{CO}$ molecules at the NP surface. Solid-state ${ }^{2} \mathrm{H}$ NMR evidenced H-D exchange between the surface of Ru NPs and ligand sites, for instance the incorporation of ${ }^{2} \mathrm{H}$ atoms in the alkylchain of hexadecylamine (HDA), as the result of a C-H activation [22]. Such reactivity has been exploited catalytically further for deuteration of different substrates, such as nitrogen [8, 12a, 23], phosphorus [24], and sulfur [25] containing compounds using Ru NP based catalysts.

${ }^{13} \mathrm{CO}$ being easily detected by IR and magic angle spinning (MAS) NMR spectroscopy techniques it is an ideal probe to provide indirect information on location and mobility of ligands at metal surface [26]. The strong coordination of phosphine ligands at Ru NP surface was evidenced to block CO mobility contrarily to the few, weak bonds involved when using a polymer as stabilizer [27]. The location of carbene [28] or betaine adduct of N-heterocyclic carbene (NHC) and carbodiimide [29] ligands at Ru NP surface was determined by similar strategies. ${ }^{13} \mathrm{CO}$ adsorption was also applied in order to investigate the surface of Pt NPs [16a].

Besides the interest of catalysis per se, it can be used as a complementary tool in order to determine the structure and composition of MNPs. Benchmark catalytic reactions can be chosen for that purpose. Surface state investigations of MNPs based on CO adsorption 
together with the comparison of the catalytic performances in $\mathrm{CO}$ oxidation allowed having a better insight in the effect of ligands on the surface of MNPs. In the case of PVP-stabilized or phosphine-capped Ru NPs CO oxidation occurred at room temperature (r.t.), but the former $\mathrm{Ru}$ system presented a rapid deactivation due to the formation of $\mathrm{RuO}_{2}$, while the later were effectively protected against bulk oxidation [27]. CO adsorption and oxidation reactions provided also interesting information of the chemical order in bimetallic RuRe NPs [30]. PVP-stabilized RuRe NPs of alloy type showed better resistance to oxidation than PVPstabilized RuRe NPs displaying a Re enriched surface and were more active towards CO dissociation than monometallic Re/PVP NPs [30a], probably as a result of the synergic effect between $\mathrm{Ru}$ and $\mathrm{Re}$. Interestingly, the dissociation of $\mathrm{CO}$ was not observed with PVPstabilized RuRe NPs displaying a Re enriched surface [30b]. Selective hydrogenation reactions are very attractive in order to correlate structural parameters of MNPs to their catalytic performances and vice versa. The numerous bonds able to be reduced by MNPs, such as $\mathrm{C}=\mathrm{C}, \mathrm{C}=\mathrm{O}$, nitro and azo groups, among others, give large possibilities to study $\mathrm{MNP}$ surfaces accurately. For instance, the hydrogenation of styrene, compound that contains alkene and arene moieties, provides a suitable system in this sense. Thus, the influence of ancillary ligands or CO on the surface of the MNPs, or the impact of the addition of a second metal in Ru NP based catalysts was studied by performing selective hydrogenation catalytic tests. For instance, using PVP-stabilized or dppb-stabilized Ru NPs (dppb= bisdiphenylphosphinobutane ) as catalyst, styrene was slowly hydrogenated at r.t., first into ethylbenzene and then into ethylcyclohexane [27]. Whilst the selective poisoning of the NPs with bridging $\mathrm{CO}$ groups led to catalysts only able to reduce the vinyl group of styrene as the result of the coordination of CO onto NP faces; a full poisoning of the surface with both terminal and bridging $\mathrm{CO}$ groups led to inactive catalysts. These results revealed that bridging CO groups and arenes compete for the same sites on the NP surface, presumably on faces. Similarly, bimetallic NP could be studied by this means [31]. Tin-decorated Ru NPs were prepared by reacting preformed $\mathrm{Ru}$ NPs, stabilized either by a polymer, Ru/PVP, or a phosphine ligand, $\mathrm{Ru} / \mathrm{dppb}$, with $\left[\left(n-\mathrm{C}_{4} \mathrm{H}_{9}\right)_{3} \mathrm{SnH}\right]$ in order to foment a tin deposit at their surface [31b]. Styrene hydrogenation investigations allowed rationalizing the influence of the surface tin on surface chemistry and catalytic activity of the Ru NPs. RuPt NPs stabilized with the dppb ligand were found to be more active $\left(\mathrm{TOF}=2.1 \mathrm{~h}^{-1}\right)$ than the monometallic $\mathrm{Ru} / \mathrm{dppb}$ ones $\left(\mathrm{TOF}=1.5 \mathrm{~h}^{-1}\right)$, in styrene hydrogenation reaction [31a]. Interestingly, these RuPt/dppb NPs were more active towards arene hydrogenation even after $\mathrm{CO}$ poisoning, thus pointing to the interest of preparing bimetallic species. In the same line, more information about the 
composition of RuPt catalysts could be ascertained by analysing the results obtained in the selective hydrogenation of trans-cinnamaldehyde, as detailed below [32].

\section{Application of organometallic nanoparticles as catalysts for hydrogenation reactions}

Ligand effects play a key role in the development and application of nanocatalysts. Electronic or steric effects or the combination of both are important parameters to design efficient catalysts. The understanding of these effects is crucial, and combining characterization analytical techniques together with computational methods has proved to be efficient to reach this aim. The versatility of the organometallic approach allowed producing a plethora of MNPs bearing a diversity of ligands suitable for catalysis. Next, a description of the use of phosphorus-, amine-, carboxylic acid-, N-heterocyclic carbene group-containing compounds, among others, as ligands to stabilize MNPs for their application as catalysts is analysed. A few examples will also describe the effect of the presence of a second metal or of a support on catalysis.

\subsection{Metal nanoparticles stabilized with phosphorus ligands.}

The surface properties of Rh NPs prepared by hydrogenation of $\left[\mathrm{Rh}\left(\eta^{3}-\mathrm{C}_{3} \mathrm{H}_{5}\right)_{3}\right]$ complex in the presence of PVP $(2.2 \mathrm{~nm}), \mathrm{PPh}_{3}(1.3 \mathrm{~nm})$, or dppb $(1.7 \mathrm{~nm})$ were compared in hydrogenation of cyclohexene as model catalytic reaction, both in colloidal and supported conditions, after immobilization onto amino-functionalized silica-coated magnetite support [18b]. PVP-stabilized Rh NPs were the most active catalyst whatever the catalytic conditions, when compared to phosphine-stabilized ones; fact attributed to the blockage of some $\mathrm{Rh}$ surface sites by the strong coordination of the phosphine ligands thus limiting the reactivity of the metallic surface. Even after several recycles of the supported nanocatalysts, Rh NPs containing phosphorus ligands displayed lower activity, underlining the strength of the ligand coordination. The PVP-stabilized Rh NPs were also evaluated in the hydrogenation of various arenes as well as levulinic acid and methyl levulinate [33]. Excellent activity and selectivity towards aromatic ring hydrogenation in mild reaction conditions (r.t.; 1 bar of $\mathrm{H}_{2}$ ) were achieved. They also showed high performance in the hydrogenation of levulinic acid and methyl levulinate in water leading quantitatively to the fuel additive $\gamma$-valerolactone under moderate reaction conditions. Interestingly, a series of very small Rh NPs (1.1-1.7 nm) were obtained using ferrocenylphosphine as stabilizing ligands [18d]. Evaluation of these Rh NPs in styrene hydrogenation showed good performance with selectivities up to $99 \%$ towards ethylbenzene, and activities differed depending on the substituents of the phosphine ligand. 
These results evidenced that the metal surface is not blocked despite the steric bulk of the ferrocenyl ligands, reasonably indicating a degree of flexibility of these ligands at the metal surface.

Roof-shaped phosphine ligands were used to stabilize Ru NPs in order to evaluate how ancillary phosphine ligands may influence their reactivity when applied as catalysts for the hydrogenation of arenes [34]. These NPs (ca. 1.1-2.1 nm) were synthesized by hydrogenassisted decomposition of $\left[\mathrm{Ru}\left(\eta^{4}-\mathrm{C}_{8} \mathrm{H}_{12}\right)\left(\eta^{6}-\mathrm{C}_{8} \mathrm{H}_{10}\right)\right]$ in THF in the presence of a series of mono and diphosphines at different ligand/Ru ratios. ${ }^{31} \mathrm{P}-\mathrm{HRMAS}$ NMR evidenced the coordination of the phosphines at the metal surface. High influence of the phosphine nature on the NP catalytic performances in the hydrogenation of $o$-methylanisole was observed. Triarylphosphine-capped Ru NPs were not or very poorly active while those with dialkylarylphosphines led to the full hydrogenation (TOF $=212 \mathrm{~h}^{-1}$ for $o$-methylanisole hydrogenation and for benzene reduction: TOF $>5000 \mathrm{~h}^{-1}$ under 3 bar of $\mathrm{H}_{2}$ and $295 \mathrm{~K}$, and TOF > 60,000 $\mathrm{h}^{-1}$ under 40 bar of $\mathrm{H}_{2}$ and $393 \mathrm{~K}$ ). This behaviour was attributed to the electronically richer NPs produced with dialkylarylphosphines and to the higher steric hindrance of triarylphosphines. Ru NPs stabilized with a secondary phosphine oxide (SPO) were applied in the hydrogenation of several aromatic model substrates in acidic or basic conditions as such a parameter is key in SPO based homogeneous catalysis [35]. The absence of such an effect for SPO-stabilized Ru NPs evidenced the non-involvement of the oxygen atom. High activity was observed for aromatic derivatives, the highest TOFs being achieved in neat conditions (TOFs up to $2700 \mathrm{~h}^{-1}$ ). Chiral SPO ligand (4,5-dihydro-3H-dinaphtho[2,1$\left.c: 1^{\prime}, 2^{\prime}-e\right]$ phosphepine-4-oxide) was successfully used to stabilize Ir NPs (synthesized by $\mathrm{H}_{2}$ reduction of $\left.\left[\operatorname{Ir}(\mathrm{OMe})\left(\mathrm{C}_{8} \mathrm{H}_{12}\right)\right]_{2} ; c a .1 .4 \mathrm{~nm}\right)$ which proved to be active for the enantioselective hydrogenation of prochiral ketones (Table 1) [19]. Extensive characterization of these Ir NPs provided interesting information on the surface chemistry of the particles and on the role of the SPO ligand. Specifically, MAS-NMR experiments through coordination of ${ }^{13} \mathrm{CO}$ highlighted the proximity of the asymmetric ligands to free active sites, located in edges and apexes, thus enabling the enantioselective formation of products. SPO is strongly bound to the NP surface and the resulting rigidity may orientate the approach of the substrate due to hydrogen bonding thus inducing the enantioselectivity.

Table 1. Enantioselective hydrogenation of prochiral ketones catalyzed by Ir NPs [a] and chiral secondary phosphine oxide $(\mathbf{L})$ employed in this study ( $S$ enantiomer is depicted). Adapted with permission from [19]. Copyright 2016 Royal Society of Chemistry. 


\begin{tabular}{|c|c|c|c|c|}
\hline \multirow[t]{15}{*}{ Substrate } & SPO ligand & Conversion $(\%)[\mathrm{b}]$ & $e e(\%)[\mathrm{b}]$ & Product configuration \\
\hline & $\mathrm{R}$ & 88 & 55 & $\mathrm{~S}$ \\
\hline & S & 47 & 52 & $\mathrm{R}$ \\
\hline & $\mathrm{R}$ & 38 & 30 & $S$ \\
\hline & $S$ & 11 & 29 & $\mathrm{R}$ \\
\hline & $\mathrm{R}$ & 90 & 22 & $S$ \\
\hline & S & 38 & 20 & $\mathrm{R}$ \\
\hline & $\mathrm{R}$ & 63 & 56 & $S$ \\
\hline & S & 14 & 39 & $\mathrm{R}$ \\
\hline & $\mathrm{R}$ & 100 & 10 & S \\
\hline & S & 100 & 8 & $\mathrm{R}$ \\
\hline & $\mathrm{R}$ & 98 & 50 & $S$ \\
\hline & $S$ & 51 & 34 & $\mathrm{R}$ \\
\hline & $\mathrm{R}$ & 100 & 26 & $S$ \\
\hline & $S$ & 100 & 30 & $\mathrm{R}$ \\
\hline
\end{tabular}

[a] Reagents and conditions: Ir NP $(0.0025 \mathrm{mmol}$ of Ir assuming \% of Ir from elemental analysis), substrate $(0.25 \mathrm{mmol})$, THF $(0.75 \mathrm{~mL}), 18 \mathrm{~h}$, r. t., 40 bar $\mathrm{H}_{2}$. [b] Conversion and \%ee were determined by GC (average of two runs).

The deoxygenation of fatty acids was investigated with supported $\mathrm{Pd}$ NPs capped with $\mathrm{PPh}_{3}$ in comparison with other supported Pd NPs stabilized with PVP or without any stabilizer on their surface (direct synthesis on the carbon support) [36]. Pd@carbon nanomaterials were found active and stable catalysts for the deoxygenation of oleic acid with different results according to the reaction process (batch or flow). Under batch conditions (20 bar of $\mathrm{H}_{2}$; $573 \mathrm{~K}$ ), the reaction efficiency depended on the $\mathrm{Pd}$ loading, the treatment of the carbon support (heating or acidic conditions) and the stabilization mode of the Pd NPs (no stabilizer; $\mathrm{PVP}$ or $\mathrm{PPh}_{3}$ ). Aromatic compounds, which can occur trough highly saturated compounds by hydrogen transfer reactions or Diels-Alder reaction of $\mathrm{C}_{6}-\mathrm{C}_{8}$ olefins, were not detected with the Pd@carbon catalysts prepared without stabilizer, octadecanol and octadecane being observed in large extents, thus indicating a deoxygenation mechanism in which the hydrocarbons are produced via both decarbonylation/decarboxylation and dehydration routes. For the $\mathrm{Pd} / \mathrm{PPh}_{3} @$ carbon and Pd/PVP@carbon nanocatalysts, the decarbonylation/decarboxylation was the only deoxygenation route. Under flow conditions (4 bar of $\mathrm{H}_{2} ; 573 \mathrm{~K}$ ), except for the Pd@carbon catalyst, the conversion of stearic acid was superior to that observed in batch conditions. The product mixture contained over $20 \%$ 
heptadecane and no octadecanol, octadecane or aromatic compounds were observed. ICPOES measurements indicated no leaching of palladium and simple washing of catalysts with mesitylene allowed their recycling without any change in conversion or product distribution.

\subsection{Metal nanoparticles stabilized with $\mathbf{N}$-heterocyclic carbenes}

The ability of N-heterocyclic carbenes to stabilize metal NPs was first investigated on Ru NPs using classical NHCs [28]. Then, the synthesis of Ru NPs was enlarged to NHC ligands displaying a variety of backbones (Figure 3) [37], and further extended to the stabilization of Pt NPs $[16 b, 38]$. The decomposition of $\left[\mathrm{Ru}\left(\eta^{4}-\mathrm{C}_{8} \mathrm{H}_{12}\right)\left(\eta^{6}-\mathrm{C}_{8} \mathrm{H}_{10}\right)\right]$ in pentane $\left(3 \mathrm{bar}\right.$ of $\mathrm{H}_{2} ; \mathrm{r}$. t.) in the presence of a N-heterocyclic carbene, i.e. 1,3-bis(2,6-diisopropylphenyl)imidazol-2ylidene (IPr) (1.5 nm /0.5eq.; $1.7 \mathrm{~nm} / 0.2$ eq. IPr) or N,N-di(tert-butyl)imidazol-2-ylidene $\left(I^{t} \mathrm{Bu}\right)\left(1.7 \mathrm{~nm} / 0.5\right.$ eq. $\left.\mathrm{I}^{\mathrm{t}} \mathrm{Bu}\right)$ [28] led to the synthesis of small NHC-stabilized Ru NPs. Full characterization, in particular by IR and NMR, proved the coordination of the ligand by the carbenic carbon and a large metal surface coverage. These carbene-capped Ru NPs were active in styrene hydrogenation with a rate significantly slower than with PVP-stabilized Ru NPs, attributed to high coverage of the metal surface. NHC-stabilized Ru NPs also catalyzed hydrogenation of other substrates (benzene derivatives, methylanisole, acetophenone) [37a] where an interesting ligand effect was observed; Ru/IPr NPs were more active than $\mathrm{Ru} / \mathrm{I}^{t} \mathrm{Bu}$ NPs, which was attributed to steric effects.

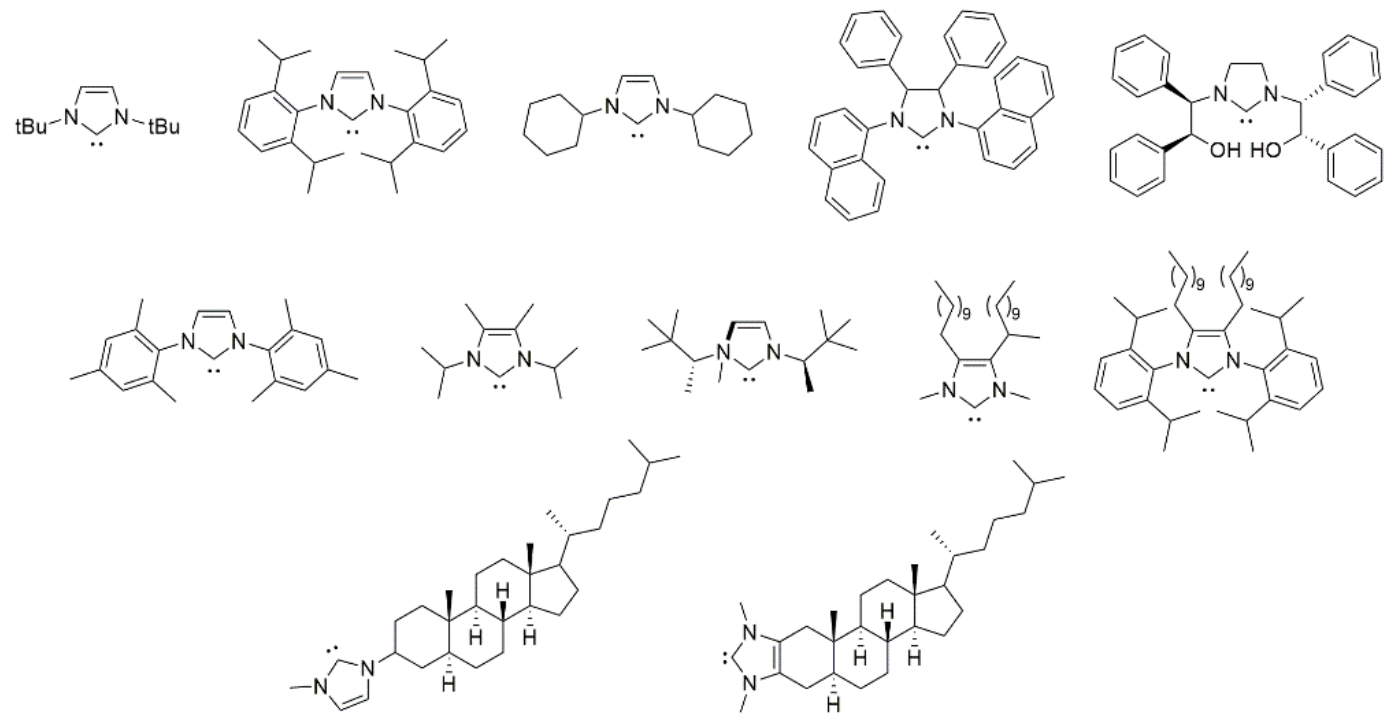

Figure 3. N-heterocyclic carbenes used as ligands to stabilize metal nanoparticles.

Several NHCs with different substituents and or backbones in their structure, including for instance chirality, showed high ability to stabilize small Ru NPs [37c-e]. Interesting ligand 
effects were evidenced but enantioselectivity was elusive when using these $\mathrm{Ru}$ based nanocatalysts. NHC-stabilized Pt NPs (1.5-1.8 nm) synthesized by hydrogenation of $\left[\mathrm{Pt}(\mathrm{dba})_{2}\right](\mathrm{dba}=$ dibenzylideneacetone $)\left(3\right.$ bar of $\mathrm{H}_{2}$; r.t. $)$ in the presence of two different carbenes (IPr or 1,3-diisopropyl-4,5-dimethylimidazol-2-ylidene $\left(\mathrm{I}^{\mathrm{i}} \mathrm{Pr}_{2} \mathrm{Me}_{2}\right)$ ) were very active for the hydrogenation of nitroaromatics in mild conditions $\left(30^{\circ} \mathrm{C} ; 1\right.$ bar of $\left.\mathrm{H}_{2}\right)$ [16b]. $\mathrm{IPr}-$ capped Pt NPs achieved chemoselective reduction of various functionalized nitroarenes including groups such as hydroxyl, benzyloxy, carbonyl and olefinic moeities as well as halogens. Also, long-chain NHCs efficiently stabilized Pt NPs [38]. The bulkiness of the ligand substituents influenced the catalytic properties of the Pt NPs. For example, the hydroboration of several acetylenes was effectively catalysed by Pt NPs bearing a bulky carbene, while Pt NPs stabilized by less steric demanding long-chain NHC displayed low catalytic performances. Nevertheless, the good selectivity for the trans-hydroborated isomer displayed with the more bulky NHC might be attributed to homogeneous species.

\subsection{Metal nanoparticles stabilized with zwitterionic ligands}

As mentioned above, the selectivity in styrene hydrogenation can depend on the availability of faces at NP surface, a size reduction being expected to increase selectivity towards the reduction of the vinyl group. This has been evidenced with betaine-stabilized Ru NPs (Figure 4) [29]. The larger NPs (ca. $1.3 \mathrm{~nm})$ totally transformed styrene into ethylcyclohexane while the smaller NPs $(c a .1 \mathrm{~nm})$ provided a partial selectivity to ethyl benzene. Such behaviour is expected for molecular complexes indicating that such $c a .1 \mathrm{~nm}$ Ru NPs display reactivity at the frontier between the molecular and the solid states.

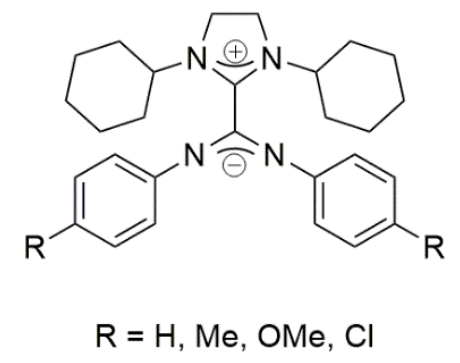

Figure 4. Zwitterionic imidazolium-amidinate (betaine) ligands.

The same zwitterionic imidazolium-amidinate ligands also stabilized Pt NPs [16c]. The strong coordination of the ligands to platinum surface was unequivocally determined by a combination of spectroscopic techniques, which were endorsed by theoretical calculations. The small Pt NPs (1.9-2.3 nm), were revealed efficient in the hydrogenation of several 
substrates containing various functional groups such as olefinic bonds, carbonyl groups, and aromatic rings, showing that electron-rich Pt NPs yield faster catalysis.

\subsection{Metal nanoparticles stabilized with fullerenes}

$\mathrm{Ru}$ nanocatalysts were prepared in a straightforward manner by decomposition of $\left[\mathrm{Ru}\left(\eta^{4}-\right.\right.$ $\left.\left.\mathrm{C}_{8} \mathrm{H}_{12}\right)\left(\eta^{6}-\mathrm{C}_{8} \mathrm{H}_{10}\right)\right]$ under $\mathrm{H}_{2}$ in the presence of $\mathrm{C}_{60}$ [39]. Fullerene $\mathrm{C}_{60}$ behaves like an electron deficient alkene giving electron-deficient properties to MNPs. Raman, XPS, EXAFS and CO adsorption experiments on $\mathrm{Ru} / \mathrm{C}_{60} \mathrm{NPs}$ synthesised using several $\mathrm{Ru} / \mathrm{C}_{60}$ ratios, pointed out that $\mathrm{Ru}$ on these samples is electron poor. These electron-deficient Ru NPs supported on Rufulleride nanospheres allowed the successive and chemoselective hydrogenation of nitrobenzene to aniline and then to cyclohexylamine. The reaction was studied at 30 bar of $\mathrm{H}_{2}$ at $80^{\circ} \mathrm{C}$ in alcoholic solvents and appeared to be solvent sensitive, proceeding faster in methanol than in other alcohols. The scope of the reaction was investigated on several substituted nitroarenes, and in all cases, the reaction proceeded very selectively as observed for nitrobenzene, first the hydrogenation of the nitro group followed by the hydrogenation of the arene ring. Density functional theory calculations suggest that the observed chemoselectivity is mainly governed by the presence of surface hydrides on the electrondeficient Ru NPs. The adsorption energy trough the nitro group or the arene moiety of nitrobenzene was calculated at several coverages of surface hydrides (Figure 5). It was found that at the threshold value of $1.5 \mathrm{H}$ per Ru surface atom, the formation of aniline is favoured due to the net preference of the $\mathrm{NO}_{2}$ coordination. Although, a ligand effect was ascertained in a further study (see below), [40] in which it was demonstrated that the unique electronic properties of the fullerene $\mathrm{C}_{60}$ based Ru NPs, affect the catalytic properties generating a very efficient catalysis for this catalytic reduction. These species also catalyzed the hydrogenation of trans-cinnamaldehyde [41]. The main product obtained using methanol and a base was cinnamyl alcohol, while an aprotic and apolar solvent decreased the activity and produced hydrocinnamaldehyde. 

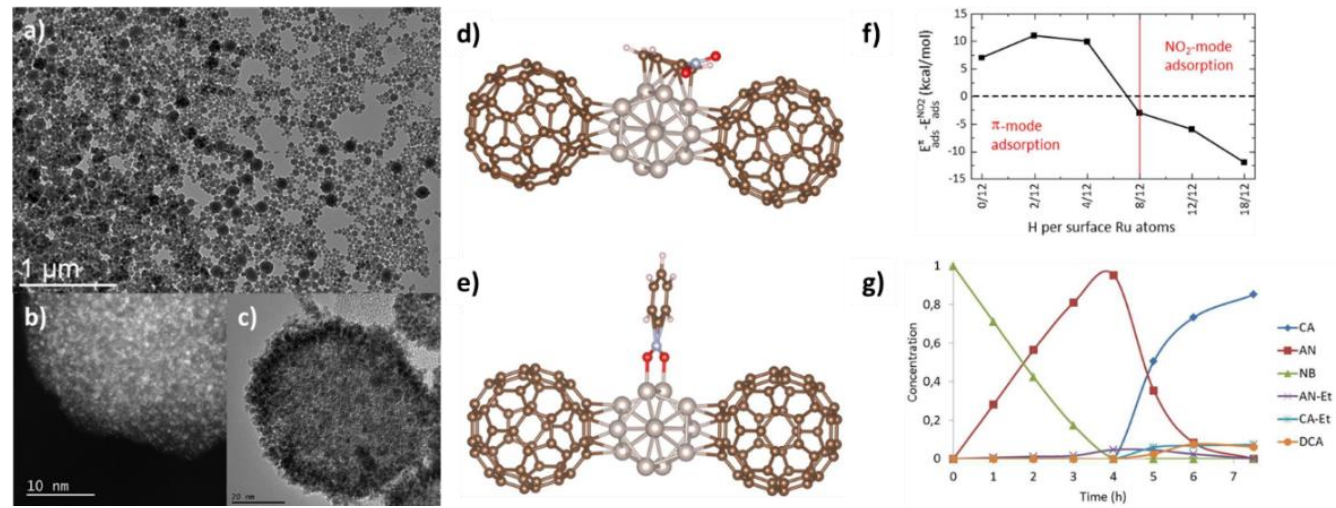

Figure 5. a) TEM micrograph of $\mathrm{Ru} / \mathrm{C}_{60} 1 / 1$. b) STEM of $\mathrm{Ru} / \mathrm{C}_{60} 1 / 1$ (scale bar $10 \mathrm{~nm}$ ). c) HREM of $\mathrm{Ru} / \mathrm{C}_{60} 20 / 1$ (scale bar $20 \mathrm{~nm}$ ). d) Side view of the $\pi$-mode coordination of a nitrobenzene molecule on a facet of a naked $2 \mathrm{C}_{60}-\mathrm{Ru}_{13}$ molecular complex. e) Side view of the $\mathrm{NO}_{2}$-mode coordination of a nitrobenzene molecule on the edge of a naked $2 \mathrm{C}_{60}-\mathrm{Ru}_{13}$ molecular complex. f) Evolution of the energy difference between the two adsorption modes with respect to the ratio of $\mathrm{H}$ per $\mathrm{Ru}$ surface atoms present on the metallic cluster. $\mathrm{g}$ ) Timeconcentration curve for nitrobenzene hydrogenation with $\mathrm{Ru} / \mathrm{C}_{60} \quad\left(\mathrm{Ru} / \mathrm{C}_{60}=10 / 1\right)$, nitrobenzene (NB), aniline (AN), cyclohexylamine (CA), N-ethylaniline (AN-Et), dicyclohexylamine (DCA), N-ethylcyclohexylamine (CA-Et). Reproduced with permission from [39b]. Copyright 2016 American Chemical Society.

Similarly, $\mathrm{Rh} / \mathrm{C}_{60}$ NPs were prepared from $\left[\mathrm{Rh}\left(\eta^{3}-\mathrm{C}_{3} \mathrm{H}_{5}\right)_{3}\right]$ giving rise to similar species, i. e. Rh-fulleride nanospheres decorated with Rh NPs, in which Rh was found to be electrondeficient by Raman and XPS analyses [18a]. This property was exploited in the selective reduction of quinoline, in which $\mathrm{Rh} / \mathrm{C}_{60} \mathrm{NPs}$ exhibited excellent activity and produced selectively the partially hydrogenated product, 1,2,3,4-tetrahydroquinoline. Thermal treatment of the samples led to a more robust catalyst, as determined by recycling tests and characterization of the spent catalysts, and also to an increase of the catalytic activity (TOF = $488 \mathrm{~h}^{-1}$ ). Theoretical calculations indicated again the crucial role of the hydride coverage of the metal NPs on the adsorption modes of the substrate and intermediates in the quinoline hydrogenation, and also, that these adsorption modes are modulated by the presence of fullerene $\mathrm{C}_{60}$, thus affecting the activity and selectivity in the catalysis.

\subsection{Metal nanoparticles stabilized with carboxylic acids}

It has been shown that carboxylic acid groups coordinate strongly to Ru NP surfaces [42] and their coordination mode has been investigated by means of spectroscopic techniques together with density functional theory calculations [4]. It has been demonstrated that $-\mathrm{COOH}$ species 
lose easily protons onto the Ru NPs surface thus providing carboxylate species and surface hydrides, as the result of the small activation barrier of $\mathrm{O}-\mathrm{H}$ bond dissociation [4a]. For example, ethanoic acid coordinates to the surface in an ethanoate form [4a]. Similarly, 1,3adamantanedicarboxylic acid coordinates as the carboxylate form [4b], but it acts also as a bridging ligand in which both $\mathrm{O}$ atoms coordinate to two surface $\mathrm{Ru}$ atoms of the NPs. The robustness of the coordination of carboxylates has been exploited in order to achieve stable catalysts. In particular, the use of multi-carboxylate ligands led to the straightforward production of 3D networks of Ru NPs, providing an interesting way to create confined spaces for catalysis. The fullerene-based hexa-adduct ligand $\mathrm{C}_{66}(\mathrm{COOH})_{12}$, provided 3D networks of $\mathrm{Ru}$ NPs (ca. $1.6 \mathrm{~nm}$ ) with an interparticle distance of $c a .2 .8 \mathrm{~nm}$ [43]. These Ru NP networks were obtained in one-step synthesis by reduction of $\left[\mathrm{Ru}\left(\eta^{4}-\mathrm{C}_{8} \mathrm{H}_{12}\right)\left(\eta^{6}-\mathrm{C}_{8} \mathrm{H}_{10}\right)\right]$ under $\mathrm{H}_{2}$ in the presence of $\mathrm{C}_{66}(\mathrm{COOH})_{12}$ hexa-adduct. Small-angle X-ray scattering (SAXS) and electron tomography analyses showed that carboxylate bridged 3D networks of Ru NPs display a short range order (Figure 6). These $\mathrm{Ru}$ assemblies catalyzed the hydrogenation of nitrobenzene. A similar methodology allowed preparing other networks of Ru NPs by using two types of functionalized polymantane compounds, bearing carboxylic acid or amine functions [4b]. Ru NP networks built up from adamantanes with carboxylic acid groups revealed to be more robust catalysts than those prepared with amine-based ligands. In addition, interesting ligands effects on catalysis were observed (see below), but especially, confinement effects were shown to increase catalytic activity in the hydrogenation of phenyl acetylene. Indeed, not only the electronic effects due to the coordination of ligands of different nature at the metal surface affected the activity and the selectivity, but also $\mathrm{Ru}$ interparticle distance governed the catalyst activity. Short distances between NPs were correlated to a higher catalytic activity.
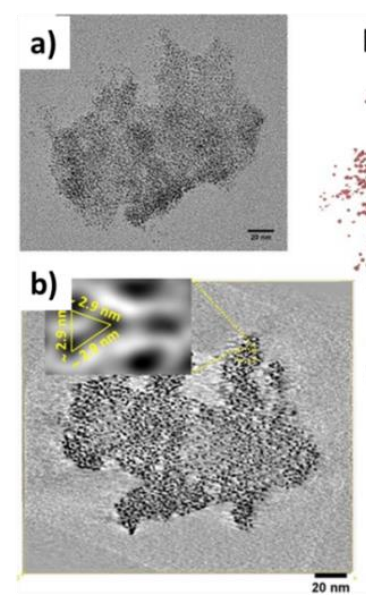

b)

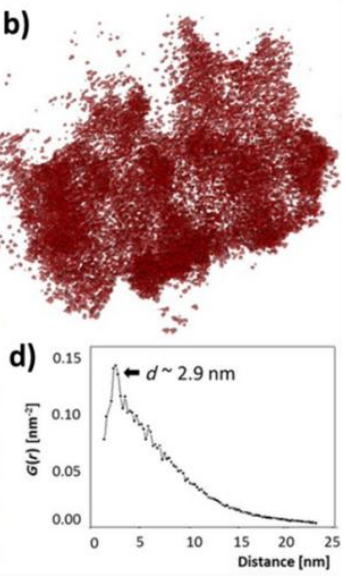

e)

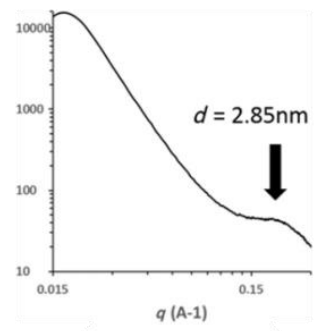

f)




Figure 6. a-d) Electron tomography analysis of a representative aggregate from the $\mathrm{Ru} / \mathrm{C}_{66}(\mathrm{COOH})_{12}$ 12:1 sample. a) TEM image from the tilt series at $0^{\circ}$ tilt. b) 3D model of the reconstructed volume showing the spatial distribution of all nanoparticles forming the aggregate. c) Typical longitudinal slice extracted from the reconstruction volume. The inset image shows the distribution of a few NPs around a reference one. The repetitive distance is around $2.9 \mathrm{~nm}$. d) Pair-distribution function of the distances between NPs calculated from their 3D coordinates extracted from electron tomography data. Primary peak shows a shortrange order around $2.9 \mathrm{~nm}$. e) SAXS spectrum of $\mathrm{Ru} / \mathrm{C}_{66}(\mathrm{COOH})_{12}$ 12:1. f) Optimized structure of the $\mathrm{C}_{66}(\mathrm{COOH})_{12}-\mathrm{Ru}_{13}-\mathrm{C}_{66}(\mathrm{COOH})_{12}$ species. Reproduced with permission from [43]. Copyright 2017 Wiley.

\subsection{Metal nanoparticles stabilized with miscellaneous ligands}

The ligands coordinated at the surface of MNPs have a large impact on catalysis. Nevertheless, still few works are reported in which a large diversity of the structure or the nature of the coordination groups of the capping agents are compared at once. In fact -other crucial parameters for catalysis than the surface properties such as size, chemical order, crystal structure, and so on can be tuned when using different stabilizing agents, making the comparison ardous. Some efforts have been done by using Ni [20] and Ru [4b, 40] NP based catalysts. A series of Ni NPs $(5-6 \mathrm{~nm})$ prepared by $\mathrm{H}_{2}$ decomposition of $\left[\mathrm{Ni}\left(\mathrm{C}_{8} \mathrm{H}_{12}\right)_{2}\right]$ complex in the presence of different stabilizers (HDA, PVP, $\mathrm{PVP} / \mathrm{PPh}_{3}$ mixture, octanoic acid (OA) and stearic acid (SA)) (Figure 7) selectively catalyzed the hydrogenation of $\alpha, \beta$-unsaturated carbonyl compounds under mild reaction conditions (THF; 3 bar of $\mathrm{H}_{2} ; 60{ }^{\circ} \mathrm{C}$; low catalyst loading) [20]. All nanocatalysts reduced only the $\mathrm{C}=\mathrm{C}$ bond of the $\alpha, \beta$-unsaturated carbonyl compounds, this chemoselectivity being attributed from the high metallic character of the $\mathrm{Ni}$ NP surface, as reflected by the high magnetic properties measured. The value of $M_{\mathrm{S}}\left(\mathrm{emu}^{-1}\right.$; $2 \mathrm{~K}$ ) and of the magnetic moments (given in brackets; $\mu_{\mathrm{B}}$ ) determined for each system are: 63.7 (0.67), 58.7 (0.61), 49.3 (0.52), 45.7 (0.48), and 34.9 (0.37) for Ni-OA@ $\mathrm{SiO}_{2}, \mathrm{Ni}-\mathrm{SA}$, $\mathrm{Ni}-\mathrm{PVP}, \mathrm{Ni}-\mathrm{HDA}$ and $\mathrm{Ni}-\mathrm{PVP} / \mathrm{PPh}_{3}$ systems, respectively. Moreover, the hydrogenation reaction rate appeared to be sensitive to ligand nature with the carboxylic acid-stabilized systems providing the best performances (Figure 7). A full kinetic investigation on the $t$ chalcone chemoselective reduction of the $\mathrm{C}=\mathrm{C}$ bond, with the best catalyst (OA-stabilized $\mathrm{Ni}$ NPs acid), revealed that the rate-determining step is the hydrogenation of the adsorbed substrate on the NP surface, following a Horiuti-Polani mechanism type. Regarding sustainable chemistry concerns, deposition of OA-capped Ni NPs onto silica $\left(\mathrm{OA} @ \mathrm{SiO}_{2}\right)$ led 
to an easily recoverable catalyst by magnetic separation that could be reused up to 10 times without significant loss of activity (Figure 7).

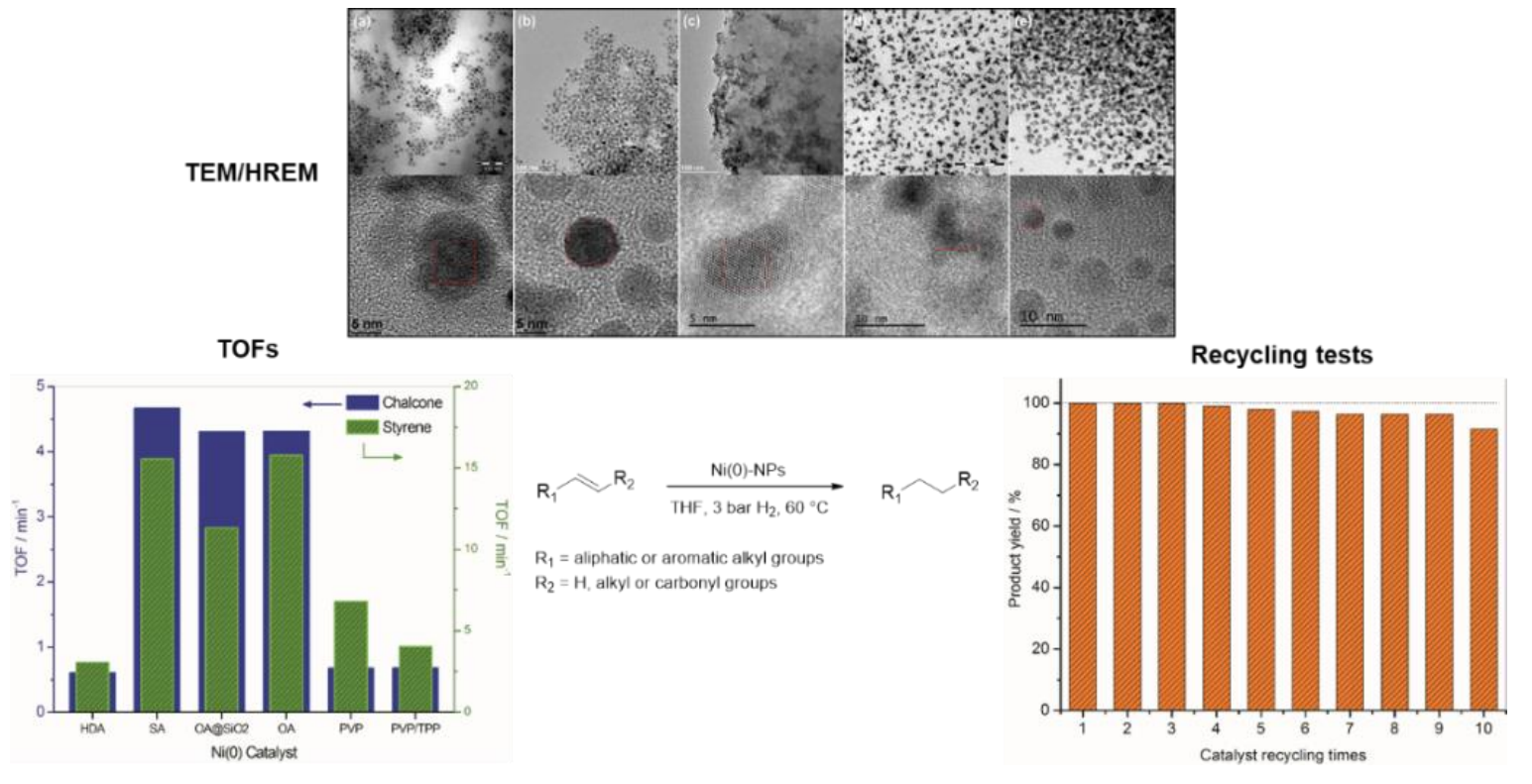

Figure 7. TEM (top) and HRTEM (bottom) images of Ni NP: (a) Ni-HDA, (b) Ni-SA, (c) Ni$\mathrm{OA} @ \mathrm{SiO}_{2}$, (d) Ni-PVP, (e) Ni-PVP/PPh 3 ; Turnover frequency (TOF) as a function of Ni(0)NP sample for $t$-chalcone (blue bars) and styrene (green bars) $(\mathrm{TOF}=$ mol product converted $/(\mathrm{mol}$ of surface $\mathrm{Ni} \times$ time $)$ calculated from the slope of plots of TON $v s$. time at low substrate conversions (up to 20\%), Reaction conditions: [substrate] $=0.416 \mathrm{~mol} \mathrm{~L}^{-1}, 12.5$ $\mu \mathrm{mol} \mathrm{Ni}, 3 \mathrm{~mL}$ THF, 3 bar $\mathrm{H}_{2}, 60{ }^{\circ} \mathrm{C}$ ); Recycling tests: Product conversion (GC) as a function of recycling times for the hydrogenation of $t$-chalcone by Ni-OA@ $\mathrm{SiO}_{2}$ catalyst (Reaction conditions: [t-chalcone] $=0.416 \mathrm{~mol} \mathrm{~L}-1,62.5 \mu \mathrm{mol} \mathrm{Ni}, 3 \mathrm{~mL}$ of THF, $3 \mathrm{bar} \mathrm{H}_{2}, 60{ }^{\circ} \mathrm{C}$ ). Reproduced with permission from [20]. Copyright 2017 Royal Society of Chemistry.

A series of Ru NPs capped with different ligands were used as catalysts in the selective hydrogenation of nitrobenzene to cyclohexylamine [40]. $\mathrm{Ru} / \mathrm{C}_{60}, \mathrm{Ru} / \mathrm{PVP}, \mathrm{Ru} / \mathrm{HDA}$, and $\mathrm{Ru} / \mathrm{IPr}$ were chosen owing to the different electronic properties of their surface, with HDA and IPr acting as donor ligands, PVP as a polymer with small interaction with the Ru NP surface, and fullerene $\mathrm{C}_{60}$ as an electron-attractor ligand. This was confirmed by the frequency of the CO band observed by IR after CO adsorption onto all the NP surfaces, while their size and structure remained similar. In all cases, the nitrobenzene reduction proceeded in a stepwise manner, producing aniline first and then cyclohexylamine, which agrees with the fact that the reaction selectivity is mainly governed by surface hydrides present onto the $\mathrm{Ru}$ NP surface, as pointed out by theoretical calculations. Nevertheless, the surface ligand affected strongly the activity and the selectivity of the catalysis. Less donor ligands promoted 
the hydrogenation of the N-phenylhydroxylamine (PHA) intermediate, rate-determining step of the reaction, while Ru NPs systems bearing more donating ligands were less active and less selective.

$\mathrm{Ru}$ NPs capped with carboxylic acid or amine functional groups displaying the same polymantane backbone, $i$. e. adamantane, bis-adamantane and diamantane, and structurally similar in terms of size, were used as catalysts in the selective hydrogenation of phenyl acetylene [4b]. All catalysts reached good selectivity towards styrene, and both selectivity and activity were significantly affected by Ru NP interparticle distance, as mentioned above, and electronic ligand effects. Ru NPs capped with $\sigma$-donor amine ligands, which provide a higher electronic density on the Ru NPs than carboxylic acid ligands, led to higher activity but with a lower selectivity towards styrene. Carboxylic acid ligands also provided more robust catalysts than amine ligands, taking into account the analyses of the spent catalysts.

\subsection{Bimetallic nanoparticles}

The organometallic approach is also an effective way for the engineering of bimetallic NPs. Adequate selection of the reaction conditions (precursor, stabilizer, reactant and temperature) allows accessing bimetallic NPs of controlled chemical order, i.e. alloy, core-shell or even MNPs decorated with another metal (like tin or platinum for instance). Compared to their monometallic counterparts, bimetallic NPs can offer synergetic effect and other selective catalytic performances due to the different surface properties induced by the metal order. Such an effect was achieved when controlling the synthesis of RuPt NPs by an adequate choice of the metal precursors based on their kinetics of decomposition. At r.t. and in the presence of PVP as stabilizer, the co-decomposition of $\left[\mathrm{Ru}\left(\eta^{4}-\mathrm{C}_{8} \mathrm{H}_{12}\right)\left(\eta^{6}-\mathrm{C}_{8} \mathrm{H}_{10}\right)\right]$ and $\left[\mathrm{Pt}(\mathrm{dba})_{2}\right]$ led to a $\mathrm{RuPt}$ alloy of $f c c$ structure [44], while using $\left[\mathrm{Pt}\left(\mathrm{CH}_{3}\right)_{2}\left(\mathrm{C}_{8} \mathrm{H}_{12}\right)\right]$ instead of [Pt(dba) $)_{2}$ gave rise to core-shell RuPt NPs [45]. The chemical segregation towards core-shell RuPt is governed by kinetic and thermodynamic (preferred location of each metal in the particle) parameters but the steric properties of the polymer which has little or no chemical interaction with the growing nanoparticles is also favorable. When keeping the same metal precursors (i.e. $\left[\mathrm{Ru}\left(\eta^{4}-\mathrm{C}_{8} \mathrm{H}_{12}\right)\left(\eta^{6}-\mathrm{C}_{8} \mathrm{H}_{10}\right)\right]$ and $\left.\left[\mathrm{Pt}\left(\mathrm{CH}_{3}\right)_{2}\left(\eta^{4}-\mathrm{C}_{8} \mathrm{H}_{12}\right)\right]\right)$, reaction conditions, and replacing the steric stabilizer by a strongly coordinating phosphorus ligand (dppb), RuPt NP with a ruthenium rich core and a disordered shell with the two metals were formed [31a]. The structure of the RuPt NPs raised from the high chemical affinity of the diphosphine ligand for both metals.

Moreover, preformed Ru NPs and Pt NPs were used as seeds for the preparation of core- 
shell RuPt and PtRu NPs, by a two step procedure. Several metal Ru/Pt ratios were used and 4-(3-phenylpropyl)pyridine (PPP) was introduced as capping ligand [32]. Besides interesting results, the implementation of these bimetallic RuPt NPs as catalysts in the hydrogenation of trans-cinnamaldehyde greatly contributed to finely determine the composition and metal distribution in these NPs and complementarily to usual chracterization techniques (IRFT, NMR, TEM, WAXS). First a higher activity was observed with higher content of platinum onto the surface (best activity for $\mathrm{Ru}_{1} \mathrm{Pt}_{4} \mathrm{NPs}$ in RuPt NPs and for $\mathrm{Pt}_{1} \mathrm{Ru}_{1}$ in PtRu NPs (Table 2). The composition and structure of the particles influenced also the selectivity. A higher selectivity was reached when ruthenium and platinum were both present at the surface of core-shell RuPt nanoparticles (partially covered core-shell $\mathrm{RuPt} \mathrm{NP} ; \mathrm{Ru}_{1} \mathrm{Pt}_{1}$ and $\mathrm{Ru}_{1} \mathrm{Pt}_{2}$ ), illustrating a synergistic effect on the selectivity between both metals.

Table 2. Cinnamaldehyde hydrogenation with bimetallic $N P s \mathrm{Ru}_{1} \mathrm{Pt}_{1}, \mathrm{Ru}_{1} \mathrm{Pt}_{2}$ and $\mathrm{Ru}_{1} \mathrm{Pt}_{4}$. Adapted with permission from [32]. Copyright 2014 Royal Society of Chemistry.

\begin{tabular}{|c|c|c|c|c|c|c|c|c|}
\hline \multicolumn{3}{|c|}{ CAL } & \multicolumn{2}{|c|}{ HCAL } & \multicolumn{2}{|c|}{$\mathrm{COL}$} & \multicolumn{2}{|c|}{ HCOL } \\
\hline Catalyst & $\begin{array}{c}\text { Time } \\
{[\mathrm{h}]}\end{array}$ & Conv. [\%] & TON & $\begin{array}{l}\text { TOF } \\
{\left[\mathrm{h}^{-1}\right]}\end{array}$ & $\begin{array}{c}\mathrm{HCAL} \\
{[\%]}\end{array}$ & $\begin{array}{c}\mathrm{HCOL} \\
{[\%]}\end{array}$ & $\begin{array}{c}\mathrm{COL} \\
{[\%]}\end{array}$ & $\begin{array}{c}\text { Acetal } \\
{[\%]}\end{array}$ \\
\hline \multirow[t]{3}{*}{$\mathrm{Ru}_{1} \mathrm{Pt}_{1}$} & 4 & 27 & 190 & 47 & 49 & 29 & 22 & n.d. \\
\hline & 6 & 42 & 298.5 & 50 & 45 & 25 & 30 & n.d. \\
\hline & 22 & 64 & 449 & 20 & 27 & 28 & 41 & 4 \\
\hline \multirow{3}{*}{$\mathrm{Ru}_{1} \mathrm{Pt}_{2}$} & 4 & 18 & 172 & 43 & 68 & 25 & 7 & n.d. \\
\hline & 6 & 24 & 226 & 38 & 58 & 25 & 15 & 2 \\
\hline & 22 & 53 & 501 & 23 & 38 & 16 & 37 & 9 \\
\hline \multirow[t]{3}{*}{$\mathrm{Ru}_{1} \mathrm{Pt}_{4}$} & 4 & 34 & 216 & 54 & 74 & 11 & 15 & n.d. \\
\hline & 6 & 44 & 282 & 47 & 68 & 13 & 18 & 1 \\
\hline & 22 & 87 & 556 & 25 & 51 & 26 & 22 & 1 \\
\hline \multirow[t]{3}{*}{$\mathrm{Pt}_{1} \mathrm{Ru}_{1}$} & 4 & 29 & 271 & 68 & 65 & 14 & 19 & 2 \\
\hline & 6 & 34 & 314 & 52 & 57 & 15 & 25 & 3 \\
\hline & 22 & 82 & 763 & 35 & 30 & 23 & 33 & 14 \\
\hline \multirow[t]{3}{*}{$\mathrm{Pt}_{1} \mathrm{Ru}_{2}$} & 4 & 43 & 283 & 71 & 71 & 12 & 16 & 1 \\
\hline & 6 & 45 & 300 & 50 & 66 & 13 & 19 & 2 \\
\hline & 22 & 80 & 527 & 24 & 38 & 24 & 30 & 8 \\
\hline \multirow{3}{*}{$\mathrm{Pt}_{1} \mathrm{Ru}_{4}$} & 4 & 14 & 94 & 23 & 59 & 19 & 22 & n.d. \\
\hline & 6 & 22 & 143 & 24 & 59 & 18 & 23 & n.d. \\
\hline & 22 & 53 & 348 & 16 & 38 & 21 & 40 & 1 \\
\hline
\end{tabular}

Reaction conditions: $2.5 \mathrm{mg}$ of bimetallic NP, cinnamaldehyde $(7.5 \mathrm{mmol})$, isopropanol $(50 \mathrm{~mL})$, $\mathrm{P}_{\mathrm{H} 2}=20$ bar, $\mathrm{T}=70^{\circ} \mathrm{C}$. Yields were determined by $\mathrm{GC}$ analysis using nonane $(3.7 \mathrm{mmol})$ as an internal standard. $\mathrm{n}$. d.: not detected. $\mathrm{TOF}=\mathrm{mol}$ substrate converted $/ \mathrm{mol}$ of metal. $\mathrm{TOF}=\mathrm{mol}$ substrate converted $/($ mol of metal $\times$ time $)$ 
Tin-decorated Ru NPs were prepared by reacting preformed Ru NPs, stabilized either by a polymer, $\mathrm{Ru} / \mathrm{PVP}$, or a diphosphine ligand, $\mathrm{Ru} / \mathrm{dppb}$, with $\left[\left(n-\mathrm{C}_{4} \mathrm{H}_{9}\right)_{3} \mathrm{SnH}\right]$ in order to foment a tin deposit at their surface [31b]. Different Sn/Ru molar ratios were applied. The formation of $\mu^{3}$-bridging "SnR" groups on the ruthenium surface was evidenced by different techniques (HREM, WAXS, IR, NMR and Mössbauer data) and corroborated by theoretical calculations. Styrene hydrogenation investigations allowed rationalizing the influence of the surface tin on surface chemistry and catalytic activity of the Ru nanoparticles. For dppb-stabilized Ru NPs, the reaction with the tin precursor was limited by the surface coverage induced by the coordination of the bulky diphosphine ligand. In the contrary, the amount of tin deposited on the $\mathrm{Ru}$ surface could be adapted using PVP instead of dppb as stabilizer. The resulting modification of the ruthenium surface led to a tuning of their surface properties, as observed through the coordination of $\mathrm{CO}$ as well as the catalytic hydrogenation of styrene. Ru/PVP/Sn cannot accommodate $\mathrm{CO}$ after the deposit of even a very low amount of tin while $\mathrm{Ru} / \mathrm{dppb} / \mathrm{Sn}$ can still accommodate terminal CO groups. The Ru/PVP/Sn NP showed a gradual variation of selectivity with increasing tin loading while only a small quantity of tin was sufficient to impede the arene hydrogenation ability of Ru/dppb nanoparticles. These results evidenced that the presence of tin adatoms on the metallic surface block some reactive sites

\subsection{Supported nanoparticles.}

The application of supported MNPs as catalysts in organic synthesis is largely explored due to synergistic effects that can arise from the association between a metal and a support. Also, immobilizing MNPs onto solid supports remains an efficient alternative for their recyclability and recovery from the reaction medium, and may favor widespread implementation of NPs in catalysis. In this context, the organometallic approach for the synthesis of MNPs provides efficient tools for the preparation of composite nanomaterials, using alumina membranes, mesoporous silica and carbon materials as non-exhaustive examples of supports. The inclusion of MNPs can be performed either by impregnation of the support using a colloidal solution of pre-formed NPs or by direct synthesis of the NPs in the presence of the support, with or without a ligand. There are also synthetic tools which allow the direct synthesis of MNPs in the presence of a support in a controlled manner, among which the functionalization of the support inspired by the ligands used to stabilize nanoparticles in solution reinforces the nanoparticle anchorage [46].

Decomposition of $\left[\mathrm{Pd}_{2}(\mathrm{dba})_{3}\right]$ directly over amino-modified silica coated magnetite particles (see Chapter 8) as support led to a nanomaterial, a palladium magnetic nanocatalyst 
containing well-dispersed Pd NPs $(3.5 \pm 0.8 \mathrm{~nm})$ exclusively on the support surface. This $\mathrm{Fe}_{3} \mathrm{O}_{4} @$ silica-Pd nanocatalyst was applied in different hydrogenation reactions. It proved to be highly active in reduction of alkenes and highly selective in the semi-hydrogenation of alkynes to alkenes without the addition of metal promoters, as reported for other Pd based catalyst [47]. Interestingly, it was also chemo- and stereoselective with more challenging benzylated propargylamine substrates, as only alkene product was obtained and side reactions such as isomerization or debenzylations were not detected, showing good overall yields under 3 bar of $\mathrm{H}_{2}$ at $27^{\circ} \mathrm{C}$ after $2 \mathrm{~h}$ (Table 3). Comparative studies with commercial Pd/C, evidenced relevant activity and selectivity, easy recoverability from the reaction media by simple application of an external magnet, negligible metal leaching, and reusability up to seven cycles, maintaining its activity and selectivity. Finally, $\mathrm{Fe}_{3} \mathrm{O}_{4} @$ silica-Pd nanocatalyst allowed optimizing the last step of a multi-step protocol (combining biocatalysis, heterogeneous metal catalysis and magnetic nanoparticles) in order to access the bitter-taste dipeptide Ala-Phe, a potential substitute for caffeine as a food additive [48]. The Pd nanocatalyst allowed removing the protective $\mathrm{Z}$ group of the $\mathrm{Z}$-Ala-Phe-OH peptide ( $\mathrm{Z}=$ benzyloxycarbonyl group; to block of amino groups) under hydrogen in mild conditions $\left(27^{\circ} \mathrm{C} ; 1\right.$ bar of $\left.\mathrm{H}_{2}\right)$. The esterified amino acid derivative was converted to the unprotected dipeptide Ala-Phe in nearly quantitative yield $\left(99 \%\right.$; $2 \mathrm{~h}$ ) releasing Phe-OMe and $\mathrm{CO}_{2}$ with almost no catalyst pollution thanks to an efficient magnetic separation of the catalyst.

Table 3. Catalytic hydrogenation of propargylamines with magnetic Pd nanocatalyst. Adapted with permission from [47]. Copyright 2015 Royal Society of Chemistry. 

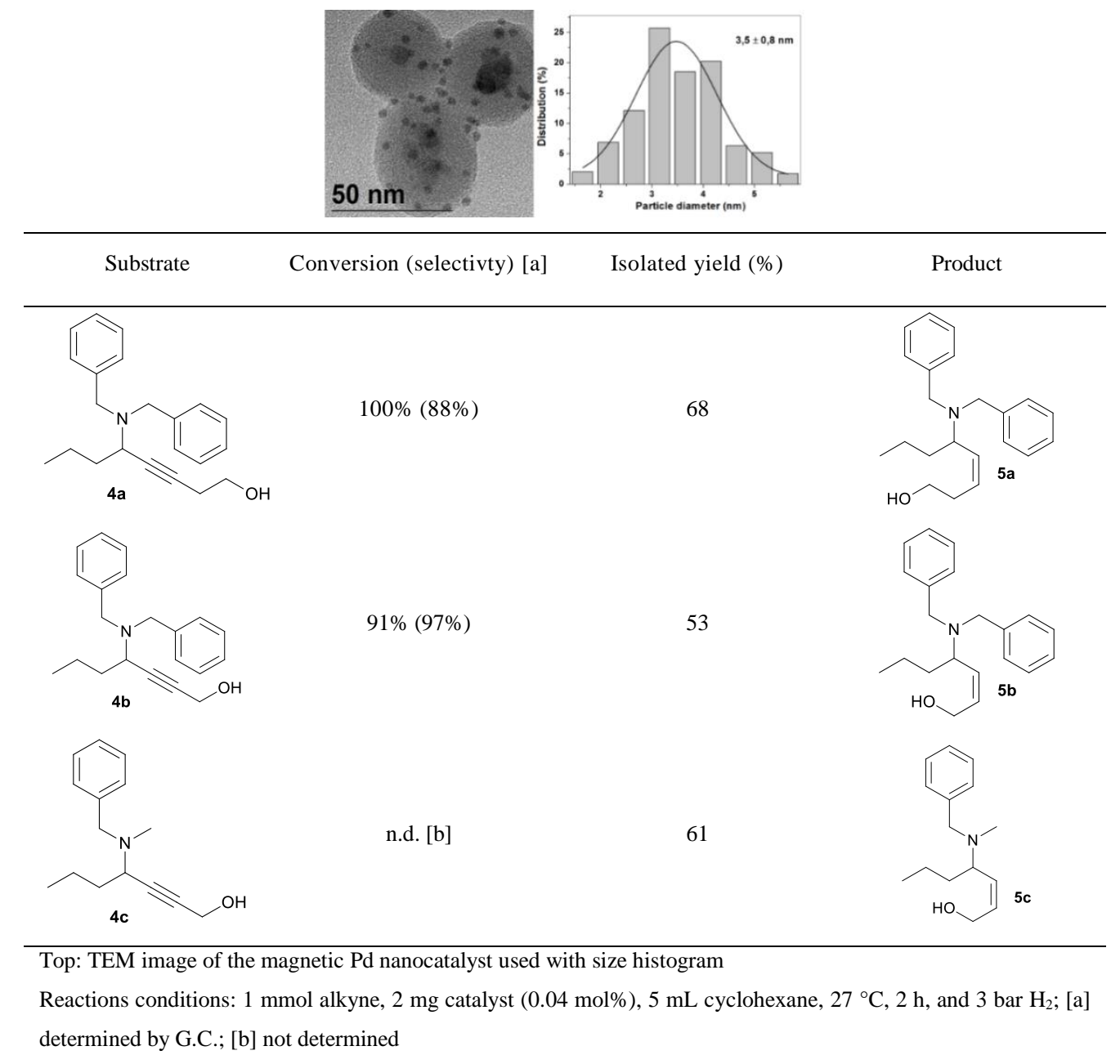

Size-controlled bimetallic NiPd NPs (co-decomposition of $\left[\mathrm{Ni}\left(\mathrm{C}_{8} \mathrm{H}_{12}\right)_{2}\right]$ and $\left[\mathrm{Pd}_{2}(\mathrm{dba})_{3}\right]$; toluene; 10 eq. $\mathrm{HDA} ; 3$ bar of $\mathrm{H}_{2} ; 110^{\circ} \mathrm{C}$ ), of different $\mathrm{Ni} / \mathrm{Pd}$ ratios were used to prepare supported NiPd catalysts by sol-immobilization onto an amino-modified magnetic silica [49]. These $\mathrm{Fe}_{3} \mathrm{O}_{4} @$ silica-NiPd nanocatalysts were applied in the hydrogenation of cyclohexene and compared to $\mathrm{Ni}$ and $\mathrm{Pd}$ monometallic systems in the same reaction conditions. A higher activity than that provided by the Pd monometallic counterpart was obtained with bimetallic nanocatalysts, the $1: 9 \mathrm{Ni} / \mathrm{Pd}$ composition achieving the highest initial turnover frequency $>50$ $000 \mathrm{~h}^{-1}$. In addition of the synergetic effect which allows saving of noble metal, magnetic separation greatly facilitated catalyst separation from the liquid products without metal leaching, leading to an efficient recycling. Direct decomposition of $\left[\mathrm{Pd}_{2}(\mathrm{dba})_{3}\right]$ over $\mathrm{Fe}_{3} \mathrm{O}_{4} @$ silica functionalized with terpyridine pendant groups provided well-dispersed Pd NPs of $c a .2 .5 \mathrm{~nm}$ on the magnetic silica support, with interesting catalytic properties in cyclohexene and $\beta$-myrcene hydrogenation [46]. High activity in mild conditions was observed for the hydrogenation of cyclohexene (TOFs up to $129000 \mathrm{~h}^{-1}$ ) as well as high selectivity for hydrogenation of $\beta$-myrcene, in which the formation of monohydrogenated 
compounds by hydrogenation of less hindered double bonds was observed. Activity and selectivity were largely increased in comparison with those obtained with a similar nanomaterial containing Pd NP supported onto an amino-modified magnetic silica, thus evidencing the influence of the functional groups used for the anchoring of the NPs onto the support, similarly to ligand effects in colloidal catalysis. Carbon materials are also largely used for the immobilization of MNPs because they offer multiple advantages including easy availability, relatively low cost, high mechanical strength and chemical stability. As for silica supports, their functionalization favours the dispersion and the anchoring of the NPs onto the surface. NP@carbon nanocatalysts were achieved by impregnation of different mesoporous carbons with colloidal solutions of $\mathrm{Ru}$ or Pd NPs (decomposition of $\left[\mathrm{Ru}\left(\eta^{4}-\mathrm{C}_{8} \mathrm{H}_{12}\right)\left(\eta^{6}-\mathrm{C}_{8} \mathrm{H}_{10}\right)\right]$ or $\left[\mathrm{Pd}_{2}(\mathrm{dba})_{3}\right]$ in THF; 3 bar of $\mathrm{H}_{2}$; r.t.) stabilized by 4-(3-phenylpropyl)pyridine or triphenyland trioctylphosphine, respectively [50]. Well-dispersed $\mathrm{Ru}$ and Pd NPs on the carbon materials (mean sizes of $c a$. 1.2-1.3 and 1.9-2.2 nm, respectively) were obtained following this procedure. Investigation in the oxidation of benzyl alcohol (in water; $80^{\circ} \mathrm{C}$ ) led to excellent conversion and selectivity (> 99\%) towards the aldehyde for both metals. Recyclability studies performed with Pd catalysts evidenced no significant loss in activity up to eight successive catalytic runs. With oxidized carbon support, hydrophilicity was shown to affect the catalytic activity, with significance depending on the hydrophobic character of the ligand used to stabilize the NPs. These carbon-supported Pd NPs proved to be efficient dual catalysts for the hydrogenation of furfural and the selective oxidation of benzyl alcohol in water under microwave irradiation. Nanocatalysts based on trioctylphosphine and triphenylphosphine-stabilized Pd NPs on oxidized carbon supports appeared the most active ones [51]. The presence of oxygen groups on the surface of the carbon support, particularly those of acidic character, improved the immobilization of the Pd NPs as well as the water affinity providing high catalytic performances (Table 4).

Table 4. Hydrogenation of furfural catalysed by carbon-supported Pd NP under microwave conditions. Adapted with permission from [51]. Copyright 2012 Royal Society of Chemistry.

\begin{tabular}{|c|c|c|c|c|}
\hline$\left\langle\prod_{0}^{H}\right.$ & $\underset{\text { Cat. }}{\stackrel{-\mathrm{CO}}{\text { (decarbonylation) }}}$ & $\langle 1\rangle$ & 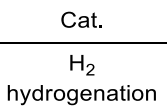 & \\
\hline Nanocatalyst & $\begin{array}{l}\text { Reaction } \\
\text { Time } \\
\text { (min) }\end{array}$ & $\begin{array}{c}\text { Conversion } \\
(\mathrm{mol} \%)\end{array}$ & $\begin{array}{l}\text { Selectivity } \\
\text { in furan } \\
(\mathrm{mol} \%)\end{array}$ & $\begin{array}{c}\text { Selectivity } \\
\text { in THF } \\
(\mathrm{mol} \%)\end{array}$ \\
\hline No catalyst & 60 & - & - & - \\
\hline $\mathrm{MB}-\mathrm{H}_{2} \mathrm{O}_{2}$ & 60 & - & - & - \\
\hline MB-1500 & 60 & - & - & - \\
\hline
\end{tabular}




\begin{tabular}{lcccc}
$\mathrm{Pd}(\mathrm{TOP}) / \mathrm{MB}-\mathrm{H}_{2} \mathrm{O}_{2}$ & 30 & $>90$ & 15 & 80 \\
$\mathrm{Pd}(\mathrm{TOP}) / \mathrm{MB}-1500$ & 30 & 75 & 20 & 72 \\
$\mathrm{Pd}\left(\mathrm{PPh}_{3}\right) / \mathrm{MB}-\mathrm{H}_{2} \mathrm{O}_{2}$ & 30 & 69 & 10 & 85 \\
$\mathrm{Pd}\left(\mathrm{PPh}_{3}\right) / \mathrm{MB}-1500$ & 30 & 65 & $<10$ & 80 \\
$\mathrm{Pd} / \mathrm{MB}-\mathrm{H}_{2} \mathrm{O}_{2}$ & 45 & 70 & 30 & 70 \\
$\mathrm{Pd} / \mathrm{MB}-1500$ & 45 & 45 & 35 & 65 \\
\hline Reaction conditions: 2 mmol furfural, $1.5 \mathrm{~mL}$ formic acid, $1.5 \mathrm{~mL}$ water, $0.1 \mathrm{~g}$ \\
catalyst, 100 ${ }^{\circ} \mathrm{C}$, Microwave Power= 100-150 W, P=150-200 psi (developed in \\
the systems). Mesoporous carbon beads (MB); Trioctylphosphine (TOP).
\end{tabular}

The hydrogenation of anthracene with carbon-supported Pd NPs was also investigated and nearly complete conversions as well as high selectivity towards the hydrogenated products without cracking or open ring derived products (naphtenics) were achieved [52]. Influence of the surface and textural properties of the carbon supports owing to their activation treatment (heating or acidic conditions) was studied. No cracking was observed for non-acidic carbon supports. Product distribution was observed as a function of reaction temperature (250$300^{\circ} \mathrm{C}$ ), with 9,10-dihydroanthracene being the main product at lower temperatures and deeper hydrogenation being achieved at intermediate temperatures $\left(300^{\circ} \mathrm{C}\right)$. $\mathrm{Pd} \mathrm{NPs}$ supported onto a carbon material heated at $2000^{\circ} \mathrm{C}$, although less active than the other catalysts at short reaction times, appeared the most effective catalyst at $300^{\circ} \mathrm{C}$ regarding the selective production of perhydroanthracene, namely the final hydrogenated product from anthracene.

Using surface-modified carbon nanotubes (CNT) as support, the influence of the confinement of RuPt nanoparticles inside CNT cavities on their catalytic properties in the hydrogenation of cinnamaldehyde was studied. The synthesis of RuPt/L/CNTs was performed in different reaction conditions from $\left[\mathrm{Ru}\left(\eta^{4}-\mathrm{C}_{8} \mathrm{H}_{12}\right)\left(\eta^{6}-\mathrm{C}_{8} \mathrm{H}_{10}\right)\right]$ and $\left[\mathrm{Pt}\left(\mathrm{CH}_{3}\right)_{2}\left(\mathrm{C}_{8} \mathrm{H}_{12}\right)\right]$ in the presence of PPP as ligand [53]. Colloidal suspension of RuPt NPs was prepared in the presence of the ligand and then used to impregnate CNT. A second route consisted in the co-decomposition of the two complexes in the presence of both the ligand and the CNTs. The best results were obtained by the impregnation method using amide-functionalized CNTs (ca. 2-2.5 nm NPs located inside the CNTs; $80 \%$ of NPs inside the CNTs for a 23 wt.\% of metal) where the confinement of the NPs inside the cavities was more important owing limited access at CNT surface. Catalytic results in the hydrogenation of cinnamaldehyde were compared to those achieved with the non-supported RuPt/PPP NPs showing higher catalytic activity and selectivity for CNT-confined RuPt/PPP NPs. A remarkable selectivity towards the formation of cinnamyl alcohol (95\%) was achieved with the catalyst presenting the highest location of NPs inside the CNTs, attributed to a confinement effect. 


\section{Conclusions}

The advantages of the organometallic approach for the design and synthesis of precisely defined mono- and bimetallic nanoparticles destined to catalysis have been illustrated through a selection of significant examples. If only examples of organic colloidal catalysis are here presented, adapted synthesis tools such as the use of amphiphilic ligands can also provide aqueous colloidal suspensions in water which proved to be of interest for catalysis, as reported in Chapter 3. Moreover, our synthetic approach also allows obtaining well-defined supported-NPs either by impregnation or by direct synthesis in the presence of a given support. This allows taking advantage of the support either for a synergy effect or/and for easier recovering/recycling of the nanocatalysts. If the ability of stabilizing ligands to increase the nanocatalyst performance has been long underestimated, recent advances evidence that tailor-made systems can improve their activity, selectivity, stability, solubility and recyclability. Varying the nature of the capping ligands enables to tune the nanoparticle surface state at both electronic and steric hindrance levels. Beside the state-of-the art techniques in solid chemistry, using usual characterization tools of molecular chemistry allows to dress a mapping of the nanoparticle surface at the molecular level. Computational chemistry dedicated to metal nanoparticles contributed greatly to the understanding of the influence of coordination chemistry at nanoparticles surface (see Chapter 15). The surface chemistry of metal nanoparticles becomes more and more understood. The recent advances offer a strong basis to continue to apprehend catalytic processes on the metal surface and explore more how these can be affected by the stabilizing molecules and/or supports. Our own experience makes us believe that continuing to take inspiration from the concepts of the different fields of catalysis (homogeneous, heterogeneous and enzymatic) should contribute to the development of more efficient and selective nanocatalysts.

\section{References}

[1] Corain, B., Schmid, G., Toshima, N. Eds., Metal Nanoclusters in Catalysis and Materials Science: The Issue of Size Control, Elsevier Science, Amsterdam, The Netherlands, 2008, p. 458.

[2] Serp, P., Philippot, K., Eds., Nanomaterials in Catalysis, Wiley-VCH Verlag GmbH \& Co. KGaA, 2013, p. 494.

[3] Cusinato, L., Martinez-Prieto, L. M., Chaudret, B., del Rosal, I., Poteau, R., Nanoscale 2016, 8, 10974-10992. 
[4] a) Gonzalez-Gomez, R., Cusinato, L., Bijani, C., Coppel, Y., Lecante, P., Amiens, C., del Rosal, I., Philippot, K., Poteau, R., Nanoscale 2019, 11, 9392-9409; b) Min, Y., Nasrallah, H., Poinsot, D., Lecante, P., Tison, Y., Martinez, H., Roblin, P., Falqui, A., Poteau, R., del Rosal, I., Gerber, I. C., Hierso, J.-C., Axet, M. R., Serp, P., Chem. Mater. 2020,_32, 6, 2365-2378;

[5] Cushing, B. L., Kolesnichenko, V. L., O'Connor, C. J., Chem. Rev. 2004, 104, 3893-3946. [6] a) Salas, G., Campbell, P. S., Santini, C. C., Philippot, K., Costa Gomes, M. F., Padua, A. A. H., Dalton Trans. 2012, 41, 13919-13926; b) Chacon, G., Dupont, J., ChemCatChem 2019, $11,333-341$.

[7] Lara, P., Philippot, K., Chaudret, B., ChemCatChem 2013, 5, 28-45.

[8] Taglang, C., Martinez-Prieto, L. M., del Rosal, I., Maron, L., Poteau, R., Philippot, K., Chaudret, B., Perato, S., Sam Lone, A., Puente, C., Dugave, C., Rousseau, B., Pieters, G., Angew. Chem., Int. Ed. 2015, 54, 10474-10477.

[9] Debouttiere, P.-J., Martinez, V., Philippot, K., Chaudret, B., Dalton Trans. 2009, $10172-$ 10174.

[10] Guerrero, M., Roucoux, A., Denicourt-Nowicki, A., Bricout, H., Monflier, E., Colliere, V., Fajerwerg, K., Philippot, K., Catal. Today 2012, 183, 34-41.

[11] Guerrero, M., Coppel, Y., Chau, N. T. T., Roucoux, A., Denicourt-Nowicki, A., Monflier, E., Bricout, H., Lecante, P., Philippot, K., ChemCatChem 2013, 5, 3802-3811.

[12] a) Martinez-Prieto, L. M., Baquero, E. A., Pieters, G., Flores, J. C., de Jesus, E., Nayral, C., Delpech, F., van Leeuwen, P. W. N. M., Lippens, G.; Chaudret, B., Chem. Commun. 2017, 53, 5850-5853; b) Debouttiere, P.-J.; Coppel, Y.; Denicourt-Nowicki, A.; Roucoux, A.; Chaudret, B.; Philippot, K., Eur. J. Inorg. Chem. 2012, 2012, 1229-1236.

[13] Amiens, C., Ciuculescu-Pradines, D., Philippot, K., Coord. Chem. Rev. 2016, 308, 409432.

[14] Kinayyigit, S., Philippot, K., in CHAPTER 4 Organometallic Approach for the Synthesis of Noble Metal Nanoparticles: Towards Application in Colloidal and Supported Nanocatalysis, (Ed. Tao, F.) The Royal Society of Chemistry, 2014, pp. 47-82.

[15] a) Martinez-Prieto, L. M., Chaudret, B., Acc. Chem. Res. 2018, 51, 376-384; b) Axet, M. R., Philippot, K., Chem. Rev. 2020, 120, 1085-1145; c) Creus, J., Drouet, S., Surinach, S., Lecante, P., Colliere, V., Poteau, R., Philippot, K., Garcia-Anton, J., Sala, X., ACS Catal. 2018, $8,11094-11102$.

[16] a) Kinayyigit, S., Lara, P., Lecante, P., Philippot, K., Chaudret, B., Nanoscale 2014, 6, 539-546; b) Lara, P., Suarez, A., Colliere, V., Philippot, K., Chaudret, B., ChemCatChem 2014, 6, 87-90; c) Martinez-Prieto, L. M., Cano, I., Marquez, A., Baquero, E. A., Tricard, S., 
Cusinato, L., del Rosal, I., Poteau, R., Coppel, Y., Philippot, K., Chaudret, B., Campora, J., van Leeuwen, P. W. N. M., Chem. Sci. 2017, 8, 2931-2941; d) Baquero, E. A., Tricard, S., Flores, J. C., de Jesus, E., Chaudret, B., Angew. Chem., Int. Ed. 2014, 53, 13220-13224; e) Lara, P., Philippot, K., Suarez, A., ChemCatChem 2019, 11, 766-771.

[17] Asensio, J. M., Tricard, S., Coppel, Y., Andres, R., Chaudret, B., de Jesus, E., Chem. Eur. J. 2017, 23, 13435-13444.

[18] a) Luo, Z., Min, Y., Nechiyil, D., Bacsa, W., Tison, Y., Martinez, H., Lecante, P., Gerber, I. C., Serp, P., Axet, M. R., Catal. Sci. Technol. 2019, 9, 6884-6898; b) Ibrahim, M., Garcia, M. A. S., Vono, L. L. R., Guerrero, M., Lecante, P., Rossi, L. M., Philippot, K., Dalton Trans. 2016, 45, 17782-17791; c) Garcia, M. A. S., Ibrahim, M.; Costa, J. C. S., Corio, P., Gusevskaya, E. V., dos Santos, E. N., Philippot, K., Rossi, L. M., Appl. Catal., A 2017, 548, 136-142; d) Ibrahim, M., Wei, M. M., Deydier, E., Manoury, E., Poli, R., Lecante, P., Philippot, K., Dalton Trans. 2019, 48, 6777-6786.

[19] Cano, I., Tschan, M. J. L., Martinez-Prieto, L. M., Philippot, K., Chaudret, B., van Leeuwen, P. W. N. M., Catal. Sci. Technol. 2016, 6, 3758-3766.

[20] Zaramello, L., Albuquerque, B. L., Domingos, J. B., Philippot, K., Dalton Trans. 2017, 46, 5082-5090.

[21] J Garcia-Anton, J., Axet, M. R., Jansat, S., Philippot, K., Chaudret, B., Pery, T., Buntkowsky, G., Limbach, H.-H., Angew. Chem., Int. Ed. 2008, 47, 2074-2078.

[22] a) Pery, T., Pelzer, K., Buntkowsky, G., Philippot, K., Limbach, H.-H., Chaudret, B., ChemPhysChem 2005, 6, 605-607; b) Rothermel, N., Roether, T., Ayvali, T., Martinez-Prieto, L. M., Philippot, K., Limbach, H.-H., Chaudret, B., Gutmann, T., Buntkowsky, G., ChemCatChem 2019, 11, 1465-1471.

[23] a) Palazzolo, A., Feuillastre, S., Pfeifer, V., Garcia-Argote, S., Bouzouita, D., Tricard, S., Chollet, C., Marcon, E., Buisson, D.-A., Cholet, S., Fenaille, F., Lippens, G., Chaudret, B., Pieters, G., Angew. Chem., Int. Ed. 2019, 58, 4891-4895; b) Pieters, G., Taglang, C., Bonnefille, E., Gutmann, T., Puente, C., Berthet, J.-C., Dugave, C., Chaudret, B., Rousseau, B., Angew. Chem., Int. Ed. 2014, 53, 230-234.

[24] Rothermel, N., Bouzouita, D., Roether, T., de Rosal, I., Tricard, S., Poteau, R., Gutmann, T., Chaudret, B., Limbach, H.-H., Buntkowsky, G., ChemCatChem 2018, 10, 4243-4247.

[25] Gao, L., Perato, S., Garcia-Argote, S., Taglang, C., Martinez-Prieto, L. M., Chollet, C., Buisson, D.-A., Dauvois, V., Lesot, P., Chaudret, B., Rousseau, B., Feuillastre, S., Pieters, G., Chem. Commun. 2018, 54, 2986-2989. 
[26] Gutmann, T., Bonnefille, E., Breitzke, H., Debouttiere, P.-J., Philippot, K., Poteau, R., Buntkowsky, G., Chaudret, B., Phys. Chem. Chem. Phys. 2013, 15, 17383-17394.

[27] Novio, F., Monahan, D., Coppel, Y., Antorrena, G., Lecante, P., Philippot, K., Chaudret, B., Chem. - Eur. J. 2014, 20, 1287-1297.

[28] Lara, P., Rivada-Wheelaghan, O., Conejero, S., Poteau, R., Philippot, K., Chaudret, B., Angew. Chem., Int. Ed. 2011, 50, 12080-12084.

[29] Martinez-Prieto, L. M., Urbaneja, C., Palma, P., Campora, J., Philippot, K., Chaudret, B., Chem. Commun. 2015, 51, 4647-4650.

[30] a) Ayvali, T., Lecante, P., Fazzini, P.-F., Gillet, A., Philippot, K., Chaudret, B., Chem. Commun. 2014, 50, 10809-10811; b) Ayvali, T., Fazzini, P.-F., Lecante, P., Mayoral, A., Philippot, K., Chaudret, B., Dalton Trans 2017, 46, 15070-15079.

[31] a) Lara, P., Ayvali, T., Casanove, M.-J., Lecante, P., Mayoral, A., Fazzini, P.-F., Philippot, K., Chaudret, B., Dalton Trans. 2013, 42, 372-382; b) Bonnefille, E., Novio, F., Gutmann, T., Poteau, R., Lecante, P., Jumas, J.-C., Philippot, K., Chaudret, B., Nanoscale 2014, 6, 9806-9816.

[32] Qi, X., Axet, M. R., Philippot, K., Lecante, P., Serp, P., Dalton Trans. 2014, 43, 92839295.

[33] Ibrahim, M., Poreddy, R., Philippot, K., Riisager, A., Garcia-Suarez, E. J., Dalton Trans. 2016, 45, 19368-19373.

[34] Gonzalez-Galvez, D., Nolis, P., Philippot, K., Chaudret, B., van Leeuwen, P. W. N. M., ACS Catal. 2012, 2, 317-321.

[35] Rafter, E., Gutmann, T., Loew, F., Buntkowsky, G., Philippot, K., Chaudret, B., van Leeuwen, P. W. N. M., Catal. Sci. Technol. 2013, 3, 595-599.

[36] Dragu, A., Kinayyigit, S., Garcia-Suarez, E. J., Florea, M., Stepan, E., Velea, S., Tanase, L., Colliere, V., Philippot, K., Granger, P., Parvulescu, V. I., Appl. Catal., A 2015, 504, 81-91. [37] a) Gonzalez-Galvez, D., Lara, P., Rivada-Wheelaghan, O., Conejero, S., Chaudret, B., Philippot, K., van Leeuwen, P. W. N. M., Catal. Sci. Technol. 2013, 3, 99-105; b) MartinezPrieto, L. M., Ferry, A., Lara, P., Richter, C., Philippot, K., Glorius, F., Chaudret, B., Chem. Eur. J. 2015, 21, 17495-17502; c) Lara, P., Martinez-Prieto, L. M., Rosello-Merino, M., Richter, C., Glorius, F., Conejero, S., Philippot, K., Chaudret, B., Nano-Struct. Nano-Objects 2016, 6, 39-45; d) Martinez-Prieto, L. M., Ferry, A., Rakers, L., Richter, C., Lecante, P., Philippot, K., Chaudret, B., Glorius, F., Chem. Commun. 2016, 52, 4768-4771; e) MartinezPrieto, L. M., Ferry, A., Rakers, L., Richter, C., Lecante, P., Philippot, K., Chaudret, B., Glorius, F., Chem. Commun. 2018, 54, 7070-7073. 
[38] Martinez-Prieto, L. M., Rakers, L., Lopez-Vinasco, A. M., Cano, I., Coppel, Y., Philippot, K., Glorius, F., Chaudret, B., van Leeuwen, P. W. N. M., Chem. - Eur. J. 2017, 23, 12779-12786.

[39] a) Leng, F., Gerber, I. C., Lecante, P., Bacsa, W., Miller, J., Gallagher, J. R., Moldovan, S., Girleanu, M., Axet, M. R., Serp, P., RSC Adv. 2016, 6, 69135-69148; b) Leng, F., Gerber, I. C., Lecante, P., Moldovan, S., Girleanu, M., Axet, M. R., Serp, P., ACS Catal. 2016, 6, 6018-6024.

[40] Axet, M. R., Conejero, S., Gerber, I. C., ACS Appl. Nano Mater. 2018, 1, 5885-5894.

[41] Leng, F., Gerber, I. C., Axet, M. R., Serp, P. C. R. Chim., C. R. Chim. 2018, 21, 346-353.

[42] Machado, B. F., Oubenali, M., Axet, M. R., Trang Nguyen, T., Tunckol, M., Girleanu, M., Ersen, O., Gerber, I. C., Serp, P., J. Catal. 2014, 309, 185-198.

[43] Leng, F., Gerber, I. C., Lecante, P., Bentaleb, A., Munoz, A., Illescas, B. M., Martin, N., Melinte, G., Ersen, O., Martinez, H., Axet, M. R., Serp, P., Chem. - Eur. J. 2017, 23, 1337913386.

[44] a) Pan, C., Dassenoy, F., Casanove, M.-J., Philippot, K., Amiens, C., Lecante, P., Mosset, A., Chaudret, B., J. Phys. Chem. B 1999, 103, 10098-10101; b) Dassenoy, F., Casanove, M. J., Lecante, P., Pan, C., Philippot, K., Amiens, C., Chaudret, B., Phys. Rev. B: Condens. Matter Mater. Phys. 2001, 63, 235407, 1-7..

[45] Lara, P., Casanove, M.-J., Lecante, P., Fazzini, P.-F., Philippot, K., Chaudret, B., J. Mater. Chem. 2012, 22, 3578-3584.

[46] Guerrero, M., Costa, N. J. S., Vono, L. L. R., Rossi, L. M., Gusevskaya, E. V., Philippot, K., J. Mater. Chem. A 2013, 1, 1441-1449.

[47] Uberman, P. M., Costa, N. J. S., Philippot, K., Carmona, R. C., Dos Santos, A. A., Rossi, L. M., Green Chem. 2014, 16, 4566-4574.

[48] Ungaro, V. A., Liria, C. W., Romagna, C. D., Costa, N. J. S., Philippot, K., Rossi, L. M., Machini, M. T., RSC Adv. 2015, 5, 36449-36455.

[49] Costa, N. J. S., Guerrero, M., Colliere, V., Teixeira-Neto, E., Landers, R., Philippot, K., Rossi, L. M., ACS Catal. 2014, 4, 1735-1742.

[50] Garcia-Suarez, E. J., Tristany, M., Garcia, A. B., Colliere, V., Philippot, K., Microporous Mesoporous Mater. 2012, 153, 155-162.

[51] Garcia-Suarez, E. J., Balu, A. M., Tristany, M., Garcia, A. B., Philippot, K., Luque, R., Green Chem. 2012, 14, 1434-1439.

[52] Pinilla, J. L., Garcia, A. B., Philippot, K., Lara, P., Garcia-Suarez, E. J., Millan, M., Fuel 2014, 116, 729-735. 
[53] Castillejos, E., Debouttiere, P.-J., Roiban, L., Solhy, A., Martinez, V., Kihn, Y., Ersen, O., Philippot, K., Chaudret, B., Serp, P., Angew. Chem., Int. Ed. 2009, 48, 2529-2533. 